ORTGIAL COMDUTHCATIONS.

\section{- A PATHOLOGICAL INQUIRY INTO THE EFFECTS OF SYPHILIS UPON THE UTERINE ORGANS.}

By.F. W. MACKENZIE, M.D.Lond., Fellow of University College, London.

iRead before the Royal Medical and Chirurgical Socicty, June 13th, 1854.]

Tre following communication contains a record of obserrations; undertaken for the purpose of determining the extent to which the uterine organs suffer from syphilis, and the character and type of the ensuing derangement. It is scarcely necessary to premise that such an inquiry is attended with many and peculiar difficulties. It is as difficult, on the one hand, to elicit a truthful narrative of facts from persons suffering from this disease respecting the history of their maladies, as it is, on the otber hand, to determine the significance and relations of such facts, when truthfulty obtained, to the many morbific influences with which they are associated, or by which they may hare been preceded. The sufferers from syphilis are commonly those who have becn exposed to the operation of many other causes besides syphilis, equally calculated to derange the uterine organs. Irregularities of living, sexual excesses, dissipation, destitution, and mental distress, are amongst some of the most constant; and, where so many conspire to a common result, it is difficult to assign the exact share of each in its production. Whilst, then, I believe that all inquiries undertaken with a view of determining the precise action of syphilis upon the uterine organs must to a certain extent be imperfect, I am yet not without hopes that some good may result from the attempt, and that a careful narrative of facts directed to this erd, if not immediately decisive of the question, will at least sorve as a basis for further inrestigation.

From the inquiries I have made, I am led to beliere that the influence of syphilis in deranging the utcrine organs is more considerable than is commonly supposed, and that the various forms of uterine derangement which result from this cause are but little known to or recognised by the profession at large. It is, however, very far from my intention to disparage the many valuable researches which have been published in this branch of professional inquiry. The morbid appenrances of the cervix uteri, occurring in connexion with syphilis, have been carefully noted and accurately recorded; the influence this disease has in disturbing the reproductive functions has received considerable attention, as also its effects upon the offspring, both immediate and remote. But many questions remain to be solved. The sereral forms of functional derangement of the uterus which follow upon syphilitic infection, and their relations to physical and vascular changes of the organ, have not, in my opinion, been either comprehensively surveyed, or satisfactorily determined; and it is upon these subjects that I have more particularly sought for information. As already stated, my inquiries have not been altogether as conclusive as could be wished; but, believing that they have put me in possession of many facts, which are not only interesting in themselves, but important in their general relations to uterine patho$\log y$, I trust that no apology is necessary in submitting them to the notice of the profession.

The cases unon which the present communication is founded are eighty in number. Nearly all of them occurred in the practice of the Lock Hospital; and, for the opportunity of making the necessary observations and inquiries, F. am indebted to the kindness of the surgeons of that institution. The histories of these cases; the condition of the uterine functions, before and after infection respectively; and the physical appearances of the cervix uteri, were in every instauce noted by myself, and, with few exceptions, is the presence of the house surgeon, to whom my written report of each case was subsequently submitted for correc- tion. I have stated this circumstance, because I am anriow to show that the record of facts embodied in this inquiry does not rest solely upon my own individual testimony, and that I was anxious to arrive at as truthful results as the nature of the subject permitted. Having thus collected all the facts I could rely upon, I proceeded in the next place to reduce them to a tabular form, placing under separate heads those relating to the syphilitic affection; to the state of the uterine organs before and after infection; to the physical condition of the cervix uteri; and to the state of the general health as obserred in each case: and, from the tables so constructed, I proceeded lastly to deduce those general conclusions which it is the more especial object of this paper to submit to professional notice. With all the care that could be taken, I fear, however, that I have not avoided many sources of fallacy. As already statcd, it is difficult to elicit the real facts of the case from persons suffering from syphilitic disease: nay morc, there is often a strong motive for wilful misrepresentation; and many of the uterine derangements met with in syphilitic patients may with reason be imputed as much to sexual excesses, etc., as to the syphilitic poison itself.

Notwithstanding the magnitude of these difficulties, it does not appear to me that they should altogether debar the attempt. I have endearoured to obviate some sources of error, by taking and contrasting the uterine history before and after syphilitic infection, rather than before and after prostitution. I have throughout closely questioned patients upon each particular fact bearing upon the inquiry, rejecting such as appeared to be doubtful; and I have endeavoured, by giving each serics of facts in different groupings, according to the social condition of each patient, to allow of a distinction being made between the effects on the uterine organs of profligacy and intemperance on the one hand, and those of the syphilitic poison on the other.

Believing the latter circumstance to be one of considerable importance to the present inquiry, I think it right to premise that, of the eighty patients whose cases I have taken, twenty-four were married, and fifty-six were single. Among the latter, it is reasouable to suppose that intemperance, irregularity of living, etc., might have co-opcrated with syphilis in producing any uterine derangements under which they may have suffered; but, in the instance of the former, such influences rould be less likely to have prevailed.

With these preliminary observations, I proceed to obserre. that, of the eighty cases, in seventy-two some form of functional derangement of the uterus was present, and in sixtyfour some physical abnormity of the cervix was observed on ocular examination. I will proceed, in the first place, to gire a detailed account of these lesions, as they respectively relate to function and structure. The former class comprehends lesions of enervation, menstruation, mucous secretion, and reproduction; the latter includes lesions of the cervical nucous membrane, affecting its rascularity and integrity, and of the body of the cervix, such as hypertrophy and induration.

\section{LESIOYS OF IYNERYATION.}

It would appear that abnormal sensibility of the uterine organs is present in a large projosition of cases of syphilis. Of the eighty I have collected, it was present in thirty-six; and of these, in twenty-four it occurred during the periods, in ten in the intervals of menstruation, and in two it was present both during and between the menstrual periods. The cerrix uteri was found morbidly sensitive on tactile examination in ten cases; and of -these, in nine this condition co-existed with uterine pain, either during or in the intervals of menstruation.

The social condition of the thirty-six patients in whom this abnormity was present is as follows. Of the whole number, eleven were married, and twenty-five were single. Of the twenty-four in which pain occurred during menstruation, six were married, and eighteen were single. Of the ten in whom it was present in the intervals of menstruation, three were married, and seven were single. The two patients 
in when there was pain both during and between the menetrual poriods wero both married.

Of the thirty-aix patients abore referred to, thirteen had experienced more or less pain during menstruation proriously to contracting syphilis, which in the majority had cubsequently increased. None of the remaining twentythree are reported to have had any uterine uneasiness, either during or in the intervals of menstruation, prior to this event.

The general character of the pain experienced was of a subdued or subacute character; rarely was it very acute; and in many cases it amounted rather to a sense of uneasinees than positive suffering. In some cases, however, the pain was rery great. In one patient, who had experienced none whatever before infection, there was intense uterine pain, extending to the groins and back, which was increased by sexual intercourse, and on going to stool. In another, who had experienced no menstrual pain before infection, menstruation was attended with very great suffering - so great, indeed, that "she could scarcely stand or contain herself during its continuance". In another, pain during menstruation, subsequently to infection, had been as acute " as if lancets were being run through her". These cases, however, it should be added, were strictly excepticnal, and were all associated with marked tenderness of the lower part of the spinal column. Regarding them, therefore, as exceptional, and probably aggravated by accessional causes, I would repeat that the general character of the uterine pain met with in these cases, whether during or in the intervals of menstruation, was mild rather than severe, and that it amounted to uneasiness rather than to positive suffering.

Such, then, being the principal facts relating to this lesion, as observed in these cases, it becomes important in the next place to consider how far we are justified in referring it specifically to the action of the syphilitic poison, rather than to the many other morbific influences to which syphilitic patients may be supposed to have been subjected. The solution of this question is attended with considerable difficulty, on account of its complexity, and the many sources of fallacy; and I fear that, in attempting it, I can only hope to arrive at an answer which may approximate to the truth.

In opposition to the probable dependence of this lesion upon syphilis, in the cases under consideration, it might be urged that the patients had been exposed to the operation of many other morbific agencics, besides the syphilitic poison, equally calculated to engender uterine disease. Of these, the most powerful would probably be sexual excesses or excitement; mental anxiety or depression; irritative disorder of distant organs, secondarily reflected upon the uterine; irregularities of living; and general deterioration of the health. Now, whilst it cannot be doubted that such causes are frequently in operation upon persons suffering from syphilis, and may co-operate with it in producing uterine disease, it yet appears to me, from the consideration of many facts, that they cannot be regarded as the cause of the lesion in the cases under examination; and I will proceed to state the grounds upon which I am led to adopt this opinion.

In the first place, I would point out the great proportiouate frequency of this lesion in the cases whose histories were investigated, amounting to forty-five per cent. of the whole number-a frequency which I bclieve to be greater than prevails in the instance of other constitutional diseases.

Secondly, it is to be observed that of the thirty-six patients in whom it was present, twenty-three, or nearly twothirds, had not experienced any uterine pain or uneasiness, before ayphilis had been contracted, either during or in the intervals of menstruation. The absence of the symptom before, and its supervention after infection, without any other obrious cause, may therefore be regarded as furnishing an argument in favour of its syphilitic origin.

Thirdly, we may infer its independence upon serual ercesses, intemperance, and irregularity of living, from the fect that its proportionate frequency was not materially greator in single than in married women, 80 far, at least, as twa inquirie have extended; for in the latter it occurred

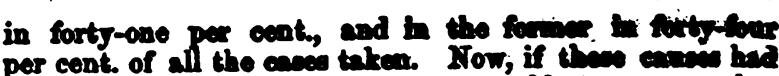
per cent. of all the caces taken. Now, if the enpose that its proportionate frequency would have been much greatere amoug single and dissolute romen, than among those who were married.

Fourthly, with regard to the influence of rarious uneasy states of mind, and causes acting generally upon the nerrous system in its production, I may remark that this view is not sustained by an examination of the facts of these cases. Had the lesion in question so arisen, we may assume that it would have been associated with other manifestations of nervous disorder. But, so far is this from being the case, we find that in upwards of one-half, or fifty-two per cent. of all the cases, no other evidence of derangement of the nerrous system was present.

Fifthly, its independence upon irritative disorder of distant organs, secondarily reflected upon the uterine, is an opinion which appears to be supported by the fact that the digestive organs, the most common seat or cause of such reflected irritation, were healthy, or at least not manifestly disordered, in the proportion of fifty-two per cent. of all the cases taken.

But further, whilst there are strong grounds for believing that these circumstances, individually, were not the cause of this lesion in these cases, there are others which go far to show that neither were they so collectively. For, in cleven per cent. of all the cases, none of them could be ascertained to have been in operation; and, bearing in mind that in all it had either followed upon infection or had been aggravated by this circumstance, we have the strongest. reasons for believing that it must have been its veritable cause, if not in all, at least in a majority of these cases.

I have endeavoured to state fairly, in the preceding paragraphs, the circumstances which would most probably favour and oppose the theory of the syphilitic origin of this lesion in the cases under consideration. I do not, however, insist upon the accuracy of the views I have been led to entertain on this subject, and have endearoured, I trust not unfairly, to support. Further observation must determine their validity; and in the meantime $I$ would venture to submit that the following proposition is deducible from the foregoing facts and considerations :-That the syphilitic poison does under certain circumstances, and in ccrtain cases, tend to produce a state of morbid sensibility of the uterine organs, manifested by uterine pain either during or in the intervals of menstruation, and this whaterer may be the social condition, habits, or modes of life of the persons infected.

\section{LESIONS OF METSTRUATION.}

The extent to which the menstrual function is disturbed by syphilis may be estimated by the fact, that serenty or seven-eighths of the patients, whose histories I have collected, were or had been suffering from some form of menstrual irregularity at the time of my inquiries; and that of these, in fifty no irregularity of this function had existed until the disease had been contracted. The following table gives a summary of the state of this function as it had been in each case subsequently to infection.

Menstruation had been entirely suppressed in........... 14

\begin{tabular}{|c|c|c|}
\hline & & interrupted in $\ldots \ldots \ldots \ldots \ldots$ \\
\hline & $"$ & 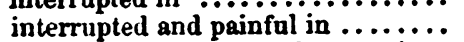 \\
\hline & 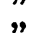 & interrupted, painful, and scanty, in.. \\
\hline " & " & morbidly recurrent in..... \\
\hline "9 & " & $\begin{array}{c}\text { morbidly recurrent, excessire, and } \\
\text { painful, in } \ldots \ldots \ldots \ldots \ldots \ldots \ldots\end{array}$ \\
\hline & $"$ & morbidly defective in...$\ldots$ \\
\hline " & " & morbidly defective an \\
\hline & $"$ & morbidly excessive in \\
\hline & $"$ & painful in \\
\hline & 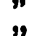 & generally irregular \\
\hline & & Porma \\
\hline
\end{tabular}

In $t w 0$ the patients were pregnant $\ldots \ldots \ldots \ldots \ldots \ldots \ldots \ldots \ldots$ 
in condition of the mem-

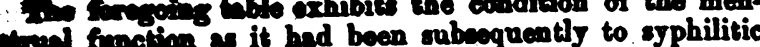
infection in each of the caces I hare taten; but it must be rimembered that of the serenty in which irregularity had thas cocurred, in trenty there had been more or less irregularity previously to this erent. I propose, therefore, to exclude these from immediate consideration, and to confine myeelf to an examination of the lesion as it cecurred in the fifty cases in which menstrual irregularity, which had not previously existed, followed upon osphilis. Of these, the following table exhibits the particular form of menstrual irregularity which occurred in cach case.

Yenstruation had been suppressed in $\ldots \ldots \ldots \ldots \ldots \ldots \ldots 10$

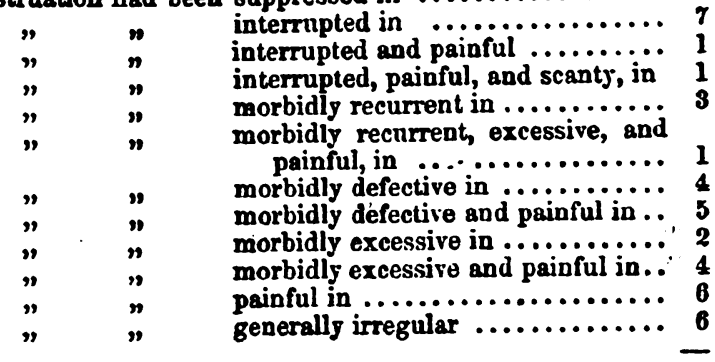

Respecting the social condition of these fifty patients, I find that sixteen were married, and thirty-four were single ; and, taking into consideration that of the whole number of cases whose histories were collected, twenty-four were married, and fifty-six were single, it follows that menstrual irregularity occurred in the proportion of sixty-six per cent. of the former, and of sixty-four per cent. of the latter after infection. A difference so trifling as to show that the irregularity observed in this function had little or nothing to do with the social condition or habits of the patients, whilst it affords an argument in favour of the opinion that it was specifically a consequence of syphilis.

The period at which this irregularity was manifested in the progress of the disease will be found to have varied in different cases; but upon the whole it would seem to have dated from an early period. In many, as in the instance of those in which there had been total suppression, it must hare occurred almost immediately afterwards. The length of time, however, which had elapsed subsequently to infection in many of these cases led me to make some additional inquiries; and on consecutively questioning on this point six patients suffering from syphilis, the duration of which had not exceeded three months, and who had been quite regular previously, I found that in four menstruation had abruptly stopped from the first period, and that in the other two, in which it had continued, in both it had been attended with greater pain from the first, and in one had been much more profuse than previously to infection. The presumption, therefore, is that menstrual irregularity is commonly an early consequence of syphilis; but there are some exceptions to this rule. Of several cases in which the date of its supervention is mentioned, I find that in one it began at the second monthly period after infection; in another at the fourth; in another at the seventh; and in one at the fifteenth. These cases, howerer, I bclieve to have been in some degree exceptional. In the great majority in which I have been enabled to ascertain the date of the occurrevce of this lesion, it has supervened during the earlier months of the disease.

The type of irregularity which follows upon syphilis is fully set forth in the preceding tables. It will be found to have presented considerable variation, but unquestionably to have been most frequently manifested in the form of suppressed, interrupted, or painful menstruation ; indeed, more than half the cases tabled will be found to consist of these lesions, or of various combinations of them. Defective menstruation, either alone or blended with various other ibermities of this function, follows next in the order of frequency; whilat abnormally recurrent and profuse merrotruation ware more rarely present in these cases.

In a large number of cases, especially in those whoce duration had been longest, some abnormal appearance of the cervix uteri was present, the nature of which is set forward in the following statement. Of the ten cases of menstrual suppression, the cervix was perfectly healthy in three, and either red, abraded, or otherwise abnormal in seren. Of seven, in which menstruation had been interrupted, it was found healthy in throc, and either rod, abraded, or otherwise abnormal in four. In one case in which menstruation had been interrupted and painful, the cervix was abraded. In one in which menstruation had been interrupted, painful, and scanty, the cervix was red and abraded. Of three cases in which menstruation had been morbidly recurrent, in each the cervix was red, and in two abraded. In one case in which menstruation had been morbidly recurrent, profuse, and painful, the cervix was perfectly healthy. Of four cases in which menstruation had been morbidly scanty or defective, the cervix was healthy in $t$ wo, enlarged in one, and red and abraded in the fourth. Of five cases in which menstruation had been morbidly scanty and painful, in two the cervix was perfectly healthy, and in three either red, abraded, or otherwise abnormal. Of two cases in which menstruation had been morbidly excessire, in one the cervix was healthy, and in one morbidly red and abraded. Of four cases in which menstruation was morbidly excessive and painful, in one the cervix was healthy, and in three, red, abraded, or otherwise abnormal ; and of six cases in which menstruation was generally irregular, in one the cervix was healthy, and in five, morbidly red, abraded, or otherwise abnormal.

From these facts, it is sufficiently obvious that various deviations from the normal appearance and condition of the cervix uteri are met with coincidently with menstrual disorder in a large number of cases of syphilis. It rould, however, be a serious error to deduce from this circumstance that such lesions of the cervix were the cause of $t^{\prime} i$ s functional disorder; for, not to mention the opposing iustances in which menstrual irregularity occurred in the absence of such lesions, it may be remarked that the abnormities of the cervix included various devintions in the colour and volume of the organ, both of which may be supposed to admit of great variation within the strict physiological limits of health; and that of the eight cases in which menstruation had continued regularly after infection, in seven some abnormity of the cervix was discovered on ocular inspection.

But further, a reference to the history of the earliest cases collected clearly proves that the functional derangement of the organ had preceded any rascular changes of the cervix. This is a point which it is important to establish; and I would therefore direct attention to the following particulars of the fire most recent cases of syphilis which were met with, and which serve also to show the probable mode and date of the transition of irritative or functional disorder into vascular disease.

CASE I. M. P., aged 20, single, applied at the Lock, March 2nd, 1854, suffering from primary symptoms of about a month's duration. She had menstruated once since contracting the disease, but the quantit, was greater than she had been previously accustomed to. The cervix was perfectly healthy, it was normal in volume, and the mucous membrane was of a pale colour, smooth, and frec from any abrasion, excoriation, or tenderness.

CASE II. E. W., aged 21, married, was admitted into the Lock, March 9 th, 1854 , suffering from primary symptoms of about a month's duration. She had menstruated once since contracting the disease, but the quantity had been so considerable as to amount almost to flooding. The cervix was found to be pale, smooth, and free from any abrasion, or ulceration.

In the preceding cases tiz cervix may be considered to have been perfectly $n$ s:n or at least free from any vascular or structural dis.a :and yet in both some degree of menstrual disordo in $\because$, surred. In the two following, 
Teanlar disence would appear to have superrened; but in Boither was there as yet any structural lesion present.

O48z IIr. F. J., aged 19, single, applied at the Lock March 2nd, 1854, suffering from primary symptoms of about month's duration. She had menstruated once since contracting the disease; and the quantity and duration were much the same as before, but it was attended with a great deal more pain. The cervix was normal in size, but its mucous membrane was of a diffused dingy red colour, and had somewhat maculated appearance. No abrasion, ulceration, or lesion of continuity, was anywhere perceptible.

CasE IV. E. T., aged 16, single, was admitted into the Lock Oct. 27th, 1853, suffering from primary symptoms of about six weeks' duration. Shc had been previously regular, but subsequently the catamenia had returned every fortnight. The mucous membrane of the cervix was abnormally red throughout, but there was no excoriation or breach of continuity.

These cases appear to illustrate the probable mode and date of the transition of irritative disorder into vascular disease; but in the following case, of perhaps somewhat longer duration, a further transition of vascular into structural disease is observable.

CASE V. E. C., aged 18, single, was admitted into the Lock Feb. 16th, 1854, suffering from primary symptoms of about six weeks' duration. She had menstruated once since, but very scantily, and the duration was shorter than usual. The cervix was normal in size, and soft, but it was of a uniformly red colour; and around the os uteri there was a bright looking excoriation or abrasion.

It appears to me that the facts of these five cases, viewed in relation to each other, throw considerable light upon many questions connected with this inquiry. In the first place, they demonstrate that functional disorder of the uterus, so far from being consequent upon, is generally antecedent to, vascular discase of the cervix; and hence that, when both coexist, they are not related to each other in the order of cause and effect, but rather as parallel effects of some probably common cause. Secondly, the mode and the probable period of the transition of irritative into vascular, and this into structural disease, appear to be clearly indicated in the histories of these cases. Lastly, the absence of all inflammatory and diseased appearances of the cervix uteri in the earliest of these cases, in which functional disorder existed coincidently with primary syphilitic discase, establishes beyond doubt that the functional disorder was not dependent upon inflammation propagated to the cervix by continuity of structure from the seat of the primary actions of syphilis; and, consequently, that it was rather due to irritation of a more specific and constitutional character.

It is only necessary to remark further, in connexion with this lesion, that, bearing in mind the above circumstances -that sexual excesses had probably little to do with its causation in these cases; that it was met with in a very large proportion of them; that, in five-sevenths of all the cases in which it was present, no such irregularity had existed until syphilis had been contracted; that it was not presumably dependent upon vascular disease of the cervix, or any other very obvious cause, - a strong case is made out in favour of the opinion that menstrual irregularity is in many instances a direct consequence of the specific actions of syphilis upon the female economy.

\section{LESIOXS OF MUCOUS BECRETION.}

Peculiar difficulties attend any attempt to determine the relations of abnormal mucous discharges from the genitourinary nucous membrane of the female to particular causes; so readily are the secretions of these parts affected by variety of circumstances. Moreover, in determining their relations to syphilis, there is this additional difficulty, that its actions are botb local and constitutional ; and hence abnormities in regard to these secretions may arise from the local irritation of the disease, rather than from its more pecific and constitutional action, which it is our more epecial object to ascertain. In the sequel, I propose to revert to this queation; and, is the man , tim I will Froceed to submit a statement of such frots malines to this lesion as ivere ascertained in the course of this inquiry.

Of the eighty patients suffering from ayphilis whose hic tories I have collected, forty-nine were or had been, at the date of my inquiries, suffering from lencorrhoea, after having contracted the disease. Of these, thirteen had not proviously suffered at all from leucorrhoes; twenty-one had but it had subsequently decreased. In eight, there had been leucorrhcea to the same amount before and after infectiou. In four, there had been leucorrhoe after infection, in which its existence previously is not noted; and three had vaginal discharges, which were probably due to the primary actions of syphilis. Of the remaining thirty-one cases, seventeen had not suffered from leucorrhoeal discharges subsequently to infection. In ten, the existence of this lesion is not noted; and in four it had existed before infection, and had subsequently diminished.

It follows, then, that forty-nine, or sixty-one per cent., of these patients were suffering from leucorrhœa in connexion with syphilis. But, subtracting from these eight in which there had beeu a corresponding amount of leucorrhœa before the disease was contracted, four in which its previous existence is not recorded, and three in which the discharges were probably occasioned by the local irritation of primary lesions, there remain only thirty-four cases in which the disease had either supervened upon syphilis, or had been manifestly increased after this event. Assuming, then, these facts to have been correctly stated,-it follows that leucorrhoea occurs in connexion with, and as a probable consequence of, syphilis, in the proportion of forty per cent. of any given number of crses of the disease.

Restricting, therefore, my observations to the thirty-four patients in which this lesion cither supervened upon or was aggravated by syphilis, it appears that eleven were married, twenty-one were single, and of two this circumstance is not recorded. It would thus appear certain that the social coudition of these patients had little or nothing to do with its causation. In fact, its relative frequency was greatest in those whose social condition was the best; being in the proportion of forty-five per cent. of married women, and thirty-seven per cent. of those who were single.

I have referred to the importance of determining specifically the relations of this lesion to the primary or local and the secondary or constitutional actions of syphilis. Many of the cases, however, partaking of a mixed character, it is difficult to determine with accuracy this question; but I have ascertained that in fourteen of the thirty-four cases the patients were suffering from primary symptoms alone; and in twenty from secondary symptoms, associated in some cases with various local lesions. The proportionate number of cases, howerer, of primary syphilis being twenty-nine, and of secondary syphilis fifty-seren, out of the eighty, it follows that the relative frequency of this lesion was greater in the former than in the latter form of the disease, being in the proportion of forty-eight per cent. in one, and thirtynine per cent. in the other.

I have treated of leucorrhca in the foregoing paragraphs in the sense in which it is ordinarily understood by the profession ; viz., as consisting in abnormal mucous or mucopurulent discharges from the genito-urinary mucous membrane, and, with the exception of discharges from syphilitic sores and other primary lesions, without any reference to its actual seat. But, in carrying out this inquiry, inasmuch as it became necessary to examine into the physical condition of the cervix uteri in every case, I was enabled to make a note of those in which an abnormal quantity of mucus was seen issuing from the interior of the cervix. This form of leucorrhoen, therefore, commonly known as cervical leucorrhcea, and by some regarded either as the essential disease or an important modification of it, admits of being analytically exmined; and its relations to particular forms of syphilis, and to the social conditions of the sereral patients whose histories were taken, etc., is set forth in the following statement:-

$\Lambda$ preternatural amount of mucus, of a viscid, atrings: 
chom the intorion of 1) corvix utari in forts-four, or mother mose than ono-half a the cighty caees. Of these, in thirtoen the patients - vere married, and in thirty-ane single; being in the proporticen of fifty-four per cent. of the former, and fifty-five per cent. of the latter, of all the cases whose histories were tren. Fifteen of the pationts in whom this lesion was mot with were suffering from primary, and twenty-nine fram secondary symptoms; which, having reference to the number of cases of primary and secondary syphilis, reapectively taken, gives a proportion in favour of its greater frequency in the former, in the ratio of fifty-six to fifty-one por cent.: a difference, however, too trifling to justify any practical conclusion.

I hare not thought it necessary to enter into an examination of the relations of this lesion to abnormal states of the cervix uteri; because, on the one hand, the relations of functional disorder to structural disease of the uterus wi!!! form the subject of a separate inquiry; and, on the other, because no deductions bearing upon the subject of this paper could be drawn from such proceeding. It must be obvious that irritative disorder of an organ will, if long continued, ultimately gire rise to vascular and structural disease, whatever may have been the character of the original irritation, whether common or specific. Admitting, therefore, that vascular disease of the cervix uteri was commonly found in connexion with leucorrhcea, no conclusion could be drawn from the circumstance in support of its syphilitic origin. Moreover, in considering this question in relation to menstrual disorders, I adduced several facts in support of the opinion that irritative or functional disorder preceded vascular change; and that, when both coexisted, they were rather to be regarded as the parallel effects of some common cause, than as respectively allied to each other as cause and effect. The analogy subsisting between the menstrual and other secretions warmants the same mode of reasoning and induction in regard to the mucous secretions of the uterine organs, and tends to show that derangements in these secretions constituting leucorrhcea have similar relations to vascular disease of the cerrix. Without, however, entering further into this question, it is submitted that sufficient evidence has been adduced to establish the fact that leucorrhoa is a common and frequent consequence of syphilitic contamination.

\section{V. LESIONS OF REPRODTCTION.}

In considering these, it will be most convenient to treat of them as they respectively affect the several functions of conception, pregnancy, parturition, and the offspring.

a. Affecting Conception. Of the eighty cases, in six only is it certain that conception occurred after infection; whilst in three others the date of conception and infection so nearly coincided, that it is impossible to say which had the priority. Of the remaining seventy-one, I have ascertained ithat fifty-two had never been pregnant either before or after infection; whilst nineteen had been pregnant before, but not after that erent.

The social condition of the fifty-two patients who had mever been pregnant, either before or after infection, is as follows:-Five were married, forty-one were single, and of six this fact was not accurately ascertained. Of the nineteen who had been pregnant before, but not after infection, thirteen were married, and six were single.

With the view of further determining the influence of syphilis in preventing conception, I have made the following calculation of the length of time which elapsed subsequently to infection without its taking place.

Of the fifty-two who had never been pregnant either before or after infection, in nineteen less than six months had elapsed; in fifteen more than six months and less than twelve months; in nine more than twelve months and less than two years; in two more than two years and less than three; in seven upwards of three years.

Of the nineteen who had been pregnant before but not after infection, in five less than six months had elapsed; in ceren more than six and less than twelve months; in four more than trolre months and lees than two jears; in throe more than two and less than three years.

In considering these data, it must be borne in mind that, although the patients referred to were syphilitic, it by no means follows that sexual intercourse had on that account been abandoned: indeed, it would appear from various circumstances which hare come to my knowledge, that infection alone is seldom a bar to its continuance; and that, in the instance of those whose intercourse is promiscuous, it is often continued for very lengthened periods after infection, and even during the existence of aggravated forms of the disease. It is in connection with such facts that the above data become alone either useful or instructive.

(b) Affecting Pregnancy. Of the eighty patients whose cases I have collected, twenty-eight had been preguant; but of these twelve had been pregnant and delivered before the date of infection, and therefore no deductions can be drawn from thom ins th thn influence of syphilis in modifying or disturbing the progress of pregnancy. This questivi, then, so far as my inquiries bear upon it, can only be dotermined by the histories of sixteen cases in whom pregnancy either preceded, followed upon, or occurred nearly simultaneously with infection, and I will proceed to consider it with reference to these three series of cases.

The cases in which pregnancy preceded infection amount altogether to six in number, and in all it proceeded to the full period without the occurrence of any unusual event. The cases in which pregnancy followed upon infection amount to seven; but, as in tivo pregnancy had occurred four times subsequently to infection, and in one twice, the absolute number of these pregnancics amounts to fourteen. Of these, in nine, it reached the full period; in two, it terminated at the eighth month; in two, at the seventh; and in one, between the fifth and sixth; menstruation having continued throughout. Of the remaining class in which pregnancy and infection occurred nearly simultaneously, amounting altogether to three, two patients went the full period, and in one pregnancy is still proceeding.

These cases, then, so far as they go, would tend to establish a pathological fact of some importance, viz., that primary syphilis is less fatal to the completion of pregnancy than secondary or constitutional syphilis. For in all cases in which patients had primary syphilis or were infected during pregnancy, it proceeded to the full period; whilst out of fourteen pregnancies occurring in women who had been infected prior to its commencement, in five the child was expelled before the full period.

(c) Affecting Parturition. The sixteen cases I have collected of patients becoming pregnant either immediately before, after, or coincidently with infection, give in tho aggregate twenty-three labours. Of these, in fourteen, no abnormity is noted; in three, it is stated that the labour was easy ; in one, difficult ; in three, attended or followed by inordinate hæuorrhage; in one, followed by a defective secretion of milk; and in one, pregnancy was still proceeding.

(d) Affecting the Offspring. Of twenty-two births, seven of the children alone were living at the date of my inquiries; and of these, five were suffering from some form of constitutional syphilis, leaving tive wuly out of the tiventy-two who had theu the appearance of being healthy.

Of the fifteen deaths, the following gives the date and probable cause of death in each.

4 children were still born.

2 children died 17 hours after lirth.

1 a weck after bith, with scaly eruption and sores, etc.

5 weeks after birth, with sore eyes $f$ - eruption.

$1 \quad " \quad$ 3 months after birth, with ecthrma. throat.

10 months after birth, with hyilrocephalus.

1

10 months after birth, with eruption \& coryza.

2 vears after lirtl, with eruption, convulsions, and inflammation of lungs.

$1 \quad$ " 3 years after birth, of phthisis.

$1 \quad$ t years after birth, of small-pox. 
"of the exen living childron, five were or had been suffaring, a follows.

had been subject to varions eruptions ever since birth.

1 had been subject to sore throat.

had been attacked with inflammation, and resication of the nates, vulva, and groins.

The date after birth at which morbid appearances first presented themselves, in sixteen children born alive, is as follows, 80 far as the circumstance is recorded in my notes.

2 looked sickly at birth, and died 17 hours afterwards.

1 was born at $\gamma$ months gestation, and died a week afterwards.

$I$ had sore eyes and an eruption at birth, and died 5 weeks afterwards.

1 died 9 months after birth, of ecthyma (date of appearance not noted).

1 dicd 9 months after birth, of tumour in throat, having been born healths.

1 died 10 months after birth, of hydrocephalus (date of appearance not noted).

1 died 2 years after birth, of eruption, convulsions, etc., having been born healthy, and continued so for is months.

1 died 3 years after birth, of phthisis, having been born healthy.

1 died 7 years after birth, of small-pox, having been born bealthy.

Of five living children suffering from constitutional syphilis :-

1 had never enjoyed good health, and had always been sub. ject to eruptions.

1 became attacked 3 months after birth with a coppery eruption.

1 is 6 years old, but constantly subject to sore throat.

1 was born healthy, but has been subject to various eruptions.

1 was born healthy, but 10 months afterwards was attacked with inflammation, and vesication of the nates, rulva, and groins.

The above cases are too few in number to justify more than the conclusion that syphilitic children may appear perfectly healthy at birth, and remain so for some time afterwards. One of these children born apparently healthy remained free from any syphilitic appcarance during six months; one during ten; and another during eighteen months.

Respecting the cause of death in cases of infantile syphilis, I may here mention the fact, that in three cousecutive examinations of the bodies of young children who had died of this disease, in each extensive disease of the mesenteric glands was met with. No other lesion of the abdominal or thoracic organs could be discovered sufficient to account for death; whilst in none had there been any symptoms referrible to the brain during life. The pathological importance of this fact I do not presume to determine, but as it appears to support an opinion entertained, I believe, by many, that scrofula very often is but a degenerated or inodified syphilis in the second generation, and points to the direction in which further inquiries may be usefully made, I have ventured to allude to the subject, and it may not be superfluous to introduce a brief outline of one of these cases; which will scrve as a type for them all.

CASE. M. A. F., a strong healthy-looking young woman, aged 21, was confined in the Paddington Infirmary March 9 th, 1854 , and gave birth to a male child. She had reached the full period of pregnancy, the labour was natural and easy, and her recovery followed without an unfavourable gymptom. The child was well developed at birth and looked healthy; but on the fourth or fifth day the mother noticed a small copper-coloured spot on the right nates. No notice, however, was taken of this; and on the 28th of March, nineteen days after delivery, both mother and child left the Infirmary apparently perfectly well. On the 1lth April 1854, the child was brought to me by the mother, looking much out of health. It was somewhat emaciated; there was an extensive copper-coloured exanthematous aruption on his face, especially around the mouth, and a cimilar eruption on the arms, genitals, and around the anus. It appeared that the child had continued wall for a weck
after learing the Infirmary; and that then (on the twrentysirth day after birth) some spots appeared around the anve and upon the genitals, which rapidly multiplied and cosand so to form red copper-coloured patches, and soon afterwards a similar eruption appeared on the face. The afterwards a similar eruption appeared on the face. The performed. On the 14th of April, three days afterwands, and performed. On the rith the date of the child's birth, it refused the breast, began to fall off in health, and became fused the breast, began to rapidly lost flesh, slept badly, had green-coloured stools, and died on the 17th April, the thirty-fourth day after birth. On a post mortem examinathe the mesenteric glands. They were enlarged and fleshy, had all red colour, and varied in size from a pea to a horsebean; they felt firm on pressure, and on being cut, pre作 tained no abnormal deposit. On questioning the mother as tained no abnormal deposit. On questioning the contracted to hot previous history, sho stated that she had contracted syphilis six months before she had become pregnant, but at the date of pregnancy, as well as subsequently, she was not. aware of having had any syphilitic symptoms, either primary the mary or secondary. It ser labour, she appeared to be remarkably healthy and strong, and free from any strumous or scrofulous taint.

[To be continued.]

Chester Place, Hyde Park Gurdens.

\section{TUMOUR OF THE UTERUS : REMOVAL.}

\section{By THOS. R. MITCHELL, M.D., F.R.C.S.I.}

In March 1854, I was asked to see Mrs. __, aged 39, who was supposed to be suffering from prolapsus uteri. On inwas supposed to be suffering from had been a quiry, I learned the following history. She had been a widow for the last twelve years, and stated that four years ago she had prolapse of the uterus, which was reduced by a medical man, who introduced an India rubber pessary, which she could not, however, bear. He accordingly withdrew it ; and recommended her to wear a pad and bandage externally. This gave great support, and she had but little inconrenience from it, there being no discharge of any kind at this time. About two years ago, she felt great pain in the back, with bearing down and great protrusion of the part, accompanied by frequent floodings, and a discharge of part, accompanied by tracter; this discharge disappeared when the menses came on, which they did regularly. She was the meen by another practitioner, who also tried to support it with a pessary; but, from the pain it gave, he was obliged to withdraw it. He prescribed tonics and nutritious diet; but, notwithstanding this, she had got weaker, and was now reduced to the lowest state. She had had three children, all naturally born, and easy labours, tho last fourteen years ago.

Her condition when seen was as follows. She complained of distressing pain in the back, with difficulty in passing urine. Her face was pale and bloodless; the eye was sunken; and a bright hectic flush was present on the cheeks. The pulse was small and quick, 96. The appetite was gone; sleep was bad, with night-sweats; the bowels were constipated; the urine was high coloured, and deposited lithates freely. She was so debilitated from the constant drain which took place, that she was quite incapacitated from following any employment. On examining, I found a large tumour, as large as a child's head, outside the vulva, very sensitive to the touch, much inflamed, and with a deeply ulcerated surface on its anterior wall, from which a quantity of purulent matter exuded. There could not be found any trace of the 03 uteri; although, on the inferior surface, a small hole was perceptible, and from which fluid trickled: this at the time I took for the os having seen cases where it became occluded. I directed a lead lotion to 